\section{AL-AZHAR}

Assiut Dental Journal
The Official Publication of The

Faculty of Dental medicine.

Al-Azhar Assiut Uniuersity.

AADJ, Vol. 2, No. 2, October (2019) - PP. 163:175

ISSn 2682-2822

\title{
Efficacy of Hydroxytyrosol as Chemopreventive Agent on Induced Hamster Buccal Pouch Carcinogenesis
}

\author{
Amr Saad Abd-Alwahab"1 ${ }^{*}$ Taha Emary Ali Ahmed ${ }^{1}$, Mohamed Gomaa Attia Zouair ${ }^{1}$
}

Codex : 19/1910

Aadj@azhar.edu.eg

\section{KEYWORDS}

$H B P$, carcinoma, hydroxytyrosol, chemoprevention, Buccal Pouch.

1. Department of Oral and Dental Pathology, Faculty of Dental Medicine ,Al-Azhar University, (Cairo, Boys), Egypt .

* Corresponding Author e-mail: AmrSaad.10@azhar.edu.eg

\begin{abstract}
Aim: It was to investigate the efficacy of hydroxytyrosol (HT) as chemopreventive agent on induced hamster buccal pouch (HBP) carcinogenesis. Subjects and Methods: Forty Syrian male hamsters five weeks old, weighing 80-120g, were divided into three groups. GI: 10 animals were left untreated. GII: 10 animals were painted with $0.5 \% 7$, 12- dimethylbenz(a)anthracene (DMBA) in paraffin oil, 3 times a week, for 8 weeks (GIIA) and14 weeks (GIIB). GIII: chemoprevention group, 20 animals in which HT was taken at week before as well as during the application of DMBA, 3 times a week on alternative days, for 8 weeks (GIIIA) and14 weeks (GIIIB). HPB mucosa were excised and trimmed to 1-2 $\mathrm{cm}$ average size, then processed for hematoxylin and eosin (H\&E) stain and Immunohistochemical (IHC) staining utilizing Bcl-2 and Bak antibodies. Results: Gross observation revealed variable changes in the treated $\left(\mathrm{G}_{(\mathrm{s})}\right)$, (GII and GIII) compared to that observed in GI. Histopathological findings revealed variations among the treated groups. IHC results regarding Bcl-2 expression revealed variability in the area percentage through-out the used groups. GI, GIIA, GIIB, GIIIA and GIIIB were $(6.77 \%, 31.58 \%, 68.37 \%, 16.07 \%, 48.81 \%)$ respectively, while IHC results regarding Bak expression revealed variability in the area percentage through-out the used groups. GI, GIIA, GIIB, GIIIA and GIIIB were $(45.32 \%, 28.58 \%, 10.38 \%, 19.32 \%, 38.72 \%)$ respectively. Conclusion: HT is considered as a promising chemopreventive agent in decrease the incidence of HBP carcinogenesis in gross observation as well as in histological examination.
\end{abstract}

\section{INTRODUCTION}

Oral epithelial dysplasia (OED) is a potentially malignant lesion, whose combination of cytological alterations and abnormal tissue architecture comprise the histopathological criteria for its diagnosis. This lesion demonstrates greater potential for undergoing malignant alteration to squamous cell carcinoma (SCC), when compared with normal epithelial tissue ${ }^{(1)}$. The incidence of oral squamous cell carcinomas (OSCCs) varies in different parts of the world and this difference is largely attributed to the exposure to risk factors specific to the $\operatorname{area}^{(2)}$. 
It has been found that, oral carcinogenesis induced by 7,12- dimethylbenz(a)anthracene (DMBA) in golden Syrian hamsters is an accepted and well recognized experimental model for studying biochemical, histopathological, immunohistochemical (IHC) and molecular alteration ${ }^{(3)}$. Extensive studies highlighted the chemopreventive effects of a diverse natural products ${ }^{(4,5)}$. Though several mechanisms were pointed out for the chemopreventive potential of natural products, the pro-apoptotic properties were documented as a major mechanism ${ }^{(6)}$. It has been found that apoptosis, programmed cell death plays a crucial role in the removal of unwanted and damaged cells from the body; $\mathrm{B}$ cell lymphoma-2 (Bcl-2) and BCL-2-antagonist/killer (Bak) have crucial role in the process of apoptosis. Deregulations in the expression of these markers are associated with abnormal proliferation ${ }^{(7)}$. Polyphenols are a wide family of compounds found in fruits and vegetables, wine, tea, cocoa, and extra-virgin olive oil, which exhibit strong antioxidant activity by scavenging different families of reactive oxygen species (ROS). One of the most effective members of the polyphenol family in terms of free radical scavenging is hydroxytyrosol $(\mathrm{HT})^{(8)}$. HT can be found in leaves and fruits of olive, extra virgin olive oil and it is specially abundant in olive oil mill waste waters from where it can be recovered ${ }^{(9)}$. Numerous studies, mostly in vitro assays and using animal models, have shown the potential role of HT for preventing additional diseases, which include protection against metabolic diseases and anti-carcinogenic activity ${ }^{(10-11)}$. In this regard, the present study was carried out to investigate the efficacy of HT as chemopreventive agent on induced HBP carcinogenesis.

\section{MATERIAL AND METHODS}

The experimental animals used in the current study were golden Syrian hamsters. They were used as model for OSCC induction utilizing DMBA as chemical carcinogen. In addition, HT was taken by oral administration one week before, as well as, during the application of DMBA, 3 times a week on alternative days for 8 and 14 weeks. After termination of experiment, an investigation using hematoxylin and eosin (H\&E) stain and IHC staining utilizing antibodies against $\mathrm{Bcl}-2$ and Bak were done.

Animals: Forty Syrian male hamsters five weeks old, weighing 80-120g were obtained from the animal house, Cairo University (Cairo, Egypt). The experimental animals were housed in standard cages with sawdust bedding under controlled environmental conditions of humidity (30-40\%), temperature $\left(20 \pm 2^{\circ} \mathrm{C}\right)$, and light (12-h light/12-h dark). All experimental animals were supplied with standard diet and water ad libitum.

Material used: DMBA (0.5\%) was obtained from Sigma-Aldrich Company, dissolved in paraffin oil. HT was obtained from Sigma-Aldrich Company, dissolved in distilled water, oral administration of HT $(0.5 \mathrm{mg} / \mathrm{kg})$ week before and during carcinoma induction was done, 3 times a week on alternative days for $8 \& 14$ weeks.

Experimental design: The experimental animals were divided into three groups $\left(\mathrm{G}_{(\mathrm{s})}\right)$. GI (negative control): 10 hamsters, fed with standard diet, without receiving any kind of treatment and served as negative controls. GII: (DMBA treated group): 10 hamsters, the rights HPB were painted with $0.5 \%$ DMBA (Sigma Aldrich) in paraffin oil using a number 4 camel hair brush three times a week. Then, the animals were randomly divided into the following 2 subgroups, GIIA: (5 hamsters) served as positive controls for 8 weeks. GIIB: (5 hamsters) served as positive controls for 14 weeks. GIII (Chemoprevention group): 20 animals, HT was taken at week before, as well as, during the application of DMBA, 3 times a week on alternative days, GIIIA: (10 hamsters) for 8 weeks, GIIIB: (10 hamsters) for 14 weeks.

Investigations: All animals were euthanized at the end of experiment. Then, hamster's head were separated and fixed in $10 \%$ buffered neutral formalin solution for $24 \mathrm{~h}$ after putting a piece of 
wood with suitable size, between hamster's teeth to prevent a wrinkling or sloughing of the hamster's mucosa during manipulation and preparation. Using a bard-parker scalpel, No 15, small surgical scissors and tweezers, the specimens were excised from right HPB mucosa and trimmed to $1-2 \mathrm{~cm}$ average size. Tissue specimens were excised, then processed for $\mathrm{H} \& \mathrm{E}$ and IHC staining.

For histological examination, the fixed specimens were dehydrated in an ascending ethanol series, embedded in paraffin wax to form paraffin blocks. Tissue sections of $4 \mu \mathrm{m}$ thickness on rotary microtome were cut, mounted on slides, processed, and stained with $\mathrm{H} \& \mathrm{E}$ for light microscopic examination.

For IHC examination, other tissue sections were cut for the application of standard labeled streptavidin- biotin method to demonstrate the expression of Bcl-2 and Bak antibodies. Paraffin embedded tissue sections were dewaxed and rehydrated through graded ethanol to distilled water. Endogenous peroxidase was blocked by incubation with $3 \% \mathrm{H}_{2} \mathrm{O}_{2}$ in methanol for $10 \mathrm{~min}$. The antigen retrieval was achieved by adding citrate buffer solution ( $\mathrm{pH}$ 6.0) and put in microwave for 3 intervals, 5 minutes each at $95^{\circ} \mathrm{C}$, followed by washing with phosphate buffered saline (PBS). The tissue sections were then received one or two drops of the primary antibodies (Bak \& Bcl-2) in a dilution of 1:100 in Tris buffer solution and incubated in a humid chamber at room temperature overnight at $4^{\circ} \mathrm{C}$. After washing with PBS, Biotinylated secondary antibody was added and incubated for $30 \mathrm{~min}$ at room temperature. After rinsing with PBS, tissue sections were received diaminobenzidine (Sigma, USA) was applied for 2-4 minutes to develop color. When acceptable color intensity was reached, the slides were washed, counter stained with haematoxylin and covered with a mounting medium. The immunostained sections were examined using light microscope to assess the prevalence of positive cases and the localization of immmunostaining within the tissues. In addition, image analysis computer system was used to assess area percentage of positive cells of the immu- nostaining. This was done in the Oral and Dental Pathology Department - Faculty of Dental Medicine - Boys- Cairo - Al-Azhar University.

\section{RESULTS}

The gross observation results of HBP mucosa of GI were pink in color with smooth surface with no observable abnormalities (Fig.1A). In GIIA, HBP mucosa showed variable changes included grayish white mucosal surface (Fig.1B) and multiple small elevated nodules surrounded with ulcerative and hemorrhagic areas (Fig.1C). In GIIB, HBP mucosa showed multiple erythematous exophytic nodules of variable sizes (Fig.1D) surrounded with area of ulceration and hemorrhage (Fig.1E) some animals appeared debilitated. In GIIIA, HBP mucosa showed variable changes included demarked grayish white patch (Fig.1F) and small exophytic nodule of normal color (Fig.1G) the animals appeared healthy. In GIIIB, HBP mucosa showed variable changes included erythematous areas with multiple exophytic nodules surrounded with ulceration and hemorrhage (Fig.1H) and exophytic masses of variable sizes. (Fig.1I).

Histopathological and IHC results: The tissue sections of HBP mucosa of experimental $\left(\mathrm{G}_{(\mathrm{s})}\right)$ showed variable results in regard to the histopathological and immunohistochemical results. In GI, histological sections, using $\mathrm{H} \& \mathrm{E}$ stain, revealed normal HBP mucosa, composed of thin stratified squamous epithelium, consists of two to four layers of squamous cells exhibiting slight keratinization (i.e.; one layer of basal cells and one to three layers of spinous and thin keratinized cells with lacking rete ridges. Sub epithelial connective tissue, muscular layer and areolar layer were seen (Fig.2A). The IHC staining using Bcl-2 antibody showed positive cytoplasmic expression in basal and suprabasal cell layers except the most superfacial layer (keratin) (6.77\%), (Fig.2B) while Bak expression showed positive cytoplasmic expression in all layers of epithelium except the most superfacial layer (keratin) (45.32\%) (Fig.2C). In GIIA, histological sections, 


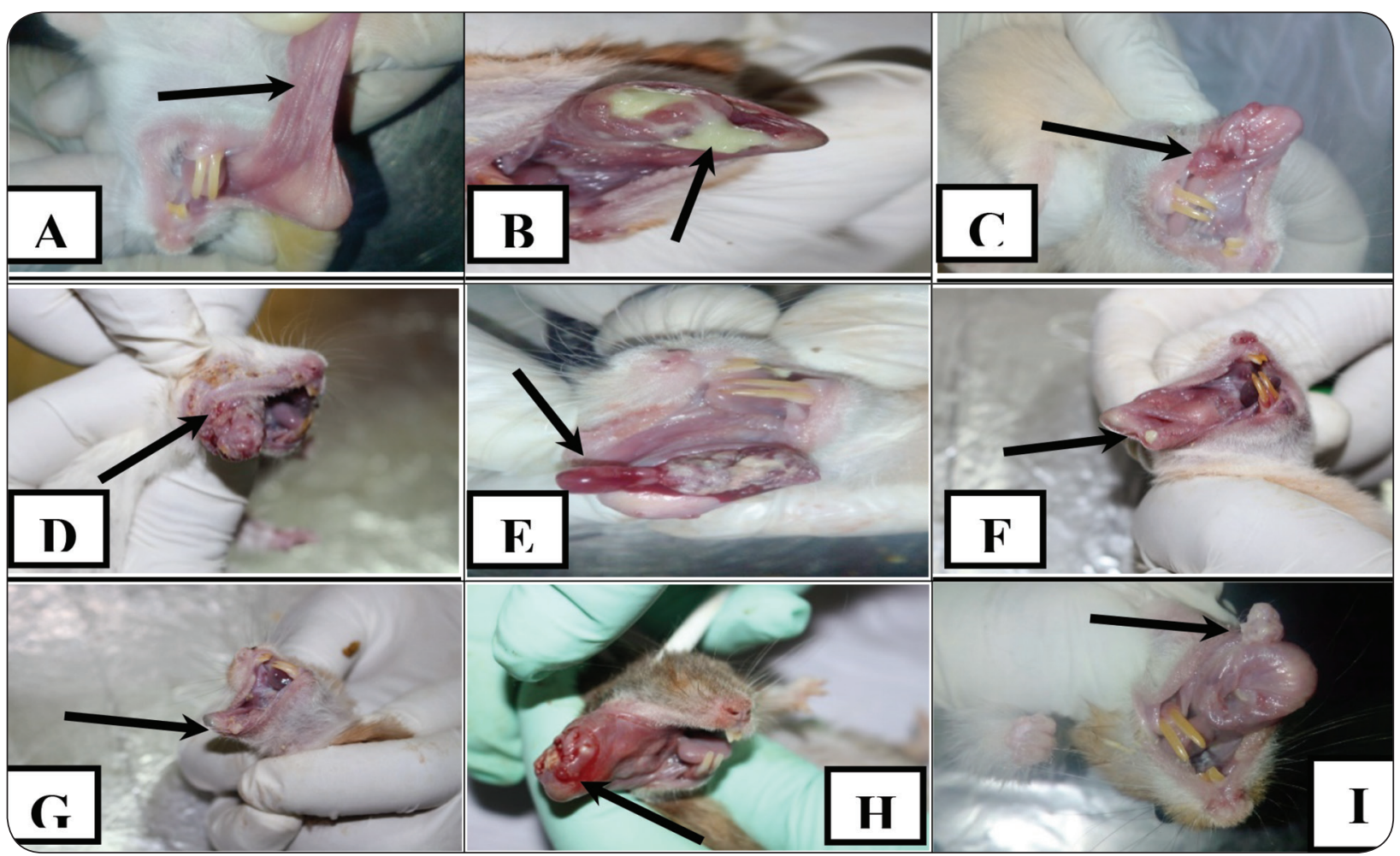

Fig. (1) (A): HBP of GI showing normal buccal pouch mucosa which appeared pink in color with smooth surface. (arrow). Fig.1(B): HBP of GIIA showing grayish white mucosal surface (arrow). Fig.1(C): HBP of GIIA showing multiple small elevated nodules surrounded with ulcerative and hemorrhagic areas (arrow). Fig.1(D): HBP of GIIB showing multiple erythematous exophytic nodules (arrow). Fig.1(E): HBP of GIIB showing variable sizes nodules surrounded with area of ulceration and hemorrhage (arrow). Fig.1(F): HBP mucosa of GIIIA showing demarked grayish white patch (arrow). Fig.1(G): HBP mucosa of GIIIA showing small exophytic nodule with area of normal color (arrow). Fig.1(H): HBP of GIIIB showing erythematous areas with multiple exophytic nodules surrounded with ulceration and hemorrhage (arrow). Fig.1(I): HBP of GIIIB showing exophytic masses of variable sizes were also seen (arrow).

using H\&E stain, HBP mucosa of 2 animals exhibited moderate epithelial dysplasia and 3 animals exhibited sever epithelial dysplasia. Dysplastic epithelium showing basilar hyperplasia, hyperchromatism cellular and nuclear pleomorphism with drop shaped rete pigs (Fig.2D). IHC staining using Bcl-2 showed positive cytoplasmic expression in all layers of epithelium except the most superfacial layer (keratin) (31.58\%) (Fig.2E) while the Bak expression showed positive cytoplasmic expression in all layers of the epithelium except the most superfacial layer (keratin) (28.58\%) (Fig.2F). In GIIB, histological sections, using H\&E stain, all samples exhibited various appearance of SCC (well differentiated as well as moderately differentiated SCC). Dysplastic features in multiple areas and provide evidence of prominent true invasion with formation of epithelial nests and keratin pearls (Fig.2G). The IHC staining using Bcl-2 showed positive cytoplasmic expression throughout the epithelial layers of the invaded nests and pearls (68.37\%) (Fig. 2H) while the Bak expression showed positive cytoplasmic expression throughout the epithelial nests (10.38\%) (Fig.2I). In GIIIA, histological sections, using H\&E stain, HBP mucosa of 3 animals exhibited normal structure, 6 animals exhibited hyperkeratosis and hyperplasia, and one animal exhibited mild epithelial dysplasia (Fig.2J). The IHC staining using Bcl-2 showed positive cytoplasmic expression throughout the epithelial layers except the most superfacial layer (keratin) (16.07\%) (Fig.2K) while the Bak expression showed positive cytoplasmic expression throughout the epithelial layers except the most superfacial layer (keratin) $(19.32 \%)$ 


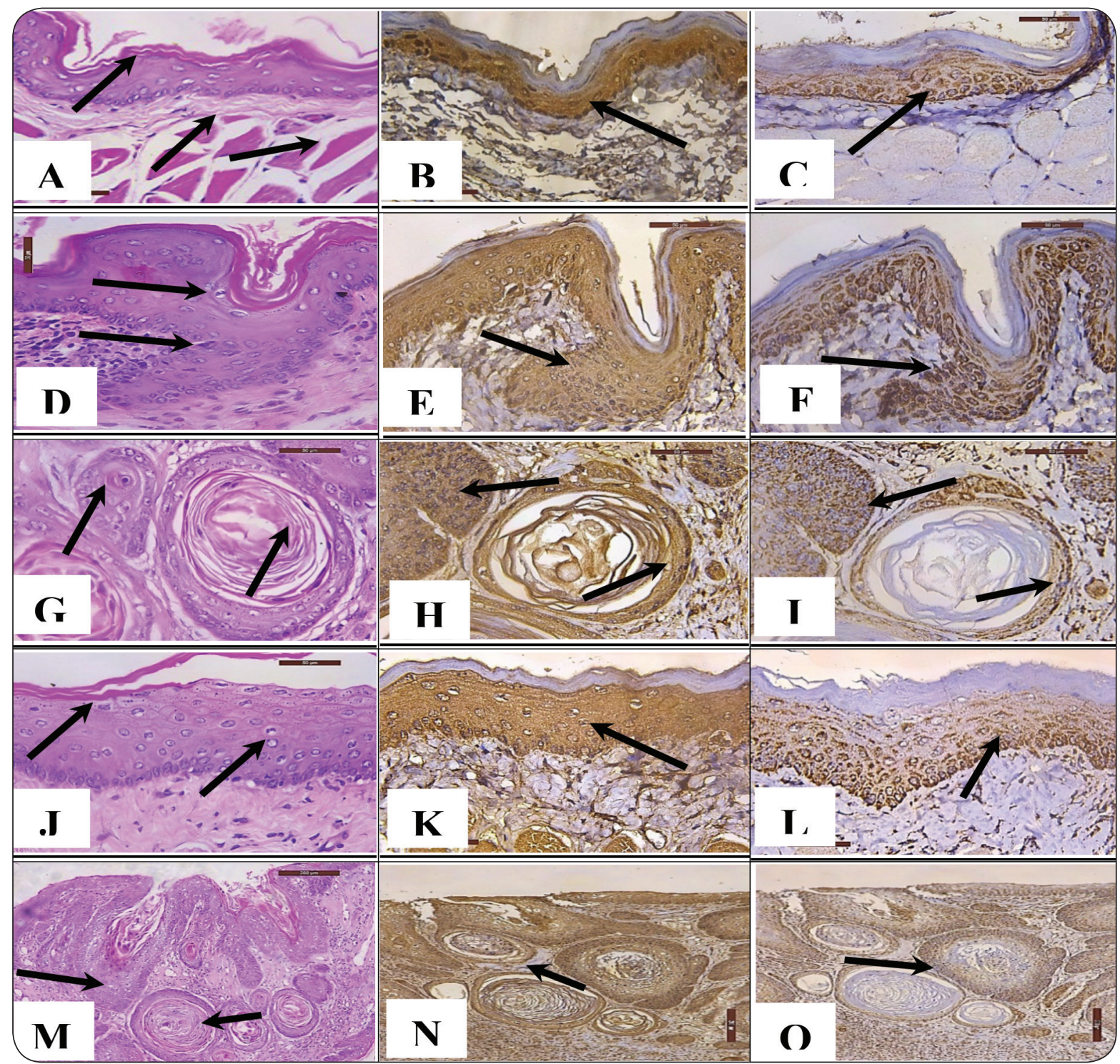

Fig.2 (A): H\&E stain of GI showing keratinized stratified squamous epithelium with flattened rete ridges, sub-epithelial connective tissue layer and muscular layer (arrows). Fig.2(B): IHC expression of Bcl-2 showing positive cytoplasmic expression mostly in basal and suprabasal epithelial layers except the most superfacial layer (keratin) (arrow). Fig.2(C): IHC expression of Bak showing positive cytoplasmic expression throughout the epithelial layers except the most superfacial layer (keratin) (arrow). Fig.2(D): H\&E stain of GIIA of HBP mucosa showing severe epithelial dysplasia including pleomorphism, hyperchromatism and abnormal mitosis (arrows). Fig.2(E): IHC expression of Bcl-2 showing positive cytoplasmic expression throughout entire epithelial layers except the most superfacial layer (keratin) (arrow). Fig.2(F): IHC expression of Bak showing positive cytoplasmic expression throughout epithelial layers except the most superfacial layer (keratin) (arrow). Fig.2(G): H\&E stain of GIIB of HBP mucosa showing well differentiated SCC, epithelial nest, and keratin pearls present in the underlying C.T. (arrows). Fig.2(H): IHC expression of Bcl-2 showing positive cytoplasmic expression throughout the epithelial nests (arrows). Fig.2(I): IHC expression of Bak showing positive cytoplasmic expression throughout the epithelial nests (arrows). Fig.2(J): H\&E stain of GIIIA of HBP mucosa showing moderate epithelial dysplasia including hyperplasia, hyperchromatism and abnormal mitosis (arrows). Fig.2(K): IHC expression of Bcl-2 showing positive cytoplasmic expression throughout the epithelial layers except the most superfacial layer (keratin) (arrow). Fig.2(L): IHC expression of Bak showing positive cytoplasmic expression throughout the epithelial layers except the most superfacial layer (keratin) (arrow). Fig.2(M): H\&E stain of GIIIB of HBP mucosa showing well differentiated SCC with hyperkeratosis, keratin pearls, and epithelial nest (arrows). Fig.2(N): IHC expression of Bcl-2 showing positive cytoplasmic expression throughout the epithelial nests (arrow). Fig.2(O): IHC expression of Bak showing positive cytoplasmic expression throughout the epithelial nests (arrow). 
(Fig.2L). In GIIIB, histological sections using H\&E stain, HBP mucosa of 2 animals exhibited moderate epithelial dysplasia, while 4 animals exhibited severe epithelial dysplasia and 4 animals exhibited well differentiated SCC (Fig.2M). The IHC staining using Bcl-2 showed positive cytoplasmic expression throughout the epithelial nests (48.81\%) (Fig.2N) while the Bak expression showed positive cytoplasmic expression throughout the epithelial nests (38.72) (Fig.2O).

Statistical analysis results of $\mathrm{Bcl}-2$ and $\mathrm{Bak}$ expression were obtained by comparing the area $\%$ of Bcl-2 and Bak expression in the $\left(\mathrm{G}_{(\mathrm{s})}\right)$ used. Bcl2 and Bak expressions at 8 weeks: Bcl-2 expression revealed high significant difference between GI and GIIA and also between GI and GIIIA where $\mathrm{p}$ value was $<0.001$ in both of them. In regard to Bak expression, there was high significant differ- ence between GI and GIIA and also between GI and GIIIA where $\mathrm{p}$ value was $<0.001$ (Chart.1.A). Bcl-2 expressions revealed high significant difference between GIIA and GIIIA where $p$ value was $<0.001$. Bak expression, revealed high significant difference between GIIA and GIIIA where $p$ value was $<0.001$ (Chart.1.B). Bcl-2 and Bak expression at 14 weeks: $\mathrm{Bcl}-2$ expression revealed high significant difference between GI and GIIB and also between GI and GIIIB where p value was $<0.001$ in both of them. Bak expression, revealed high significant difference between GI and GIIB where $p$ value was $<0.001$. Also there was, significant difference between GI and GIIIB where p value was 0.014 (Chart.2.A). Bcl-2 expressions revealed high significant difference between GIIB and GIIIB where $\mathrm{p}$ value was $<0.001$. Bak expression, revealed high significant difference between GIIB and GIIIB where $p$ value was $<0.001$ (Chart.2.B).

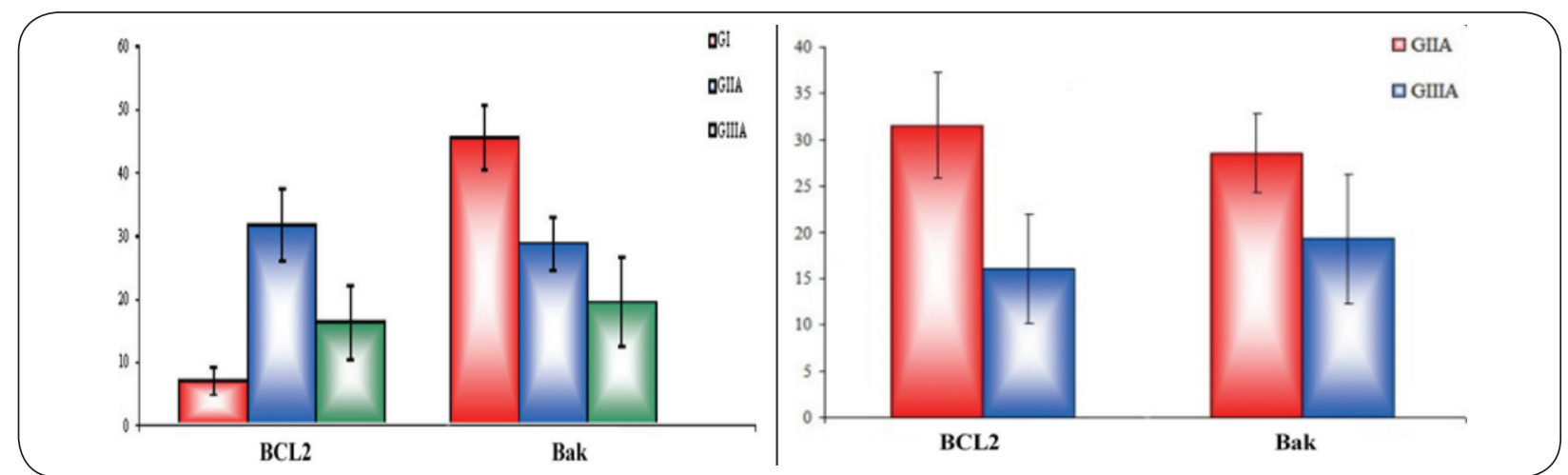

Chart (1): Bar chart representing mean area \% results of Bcl-2 \& Bak (A) in GI, GIIA \& GIIIA at 8 weeks (B) in GIIA \& GIIIA at 8 weeks.

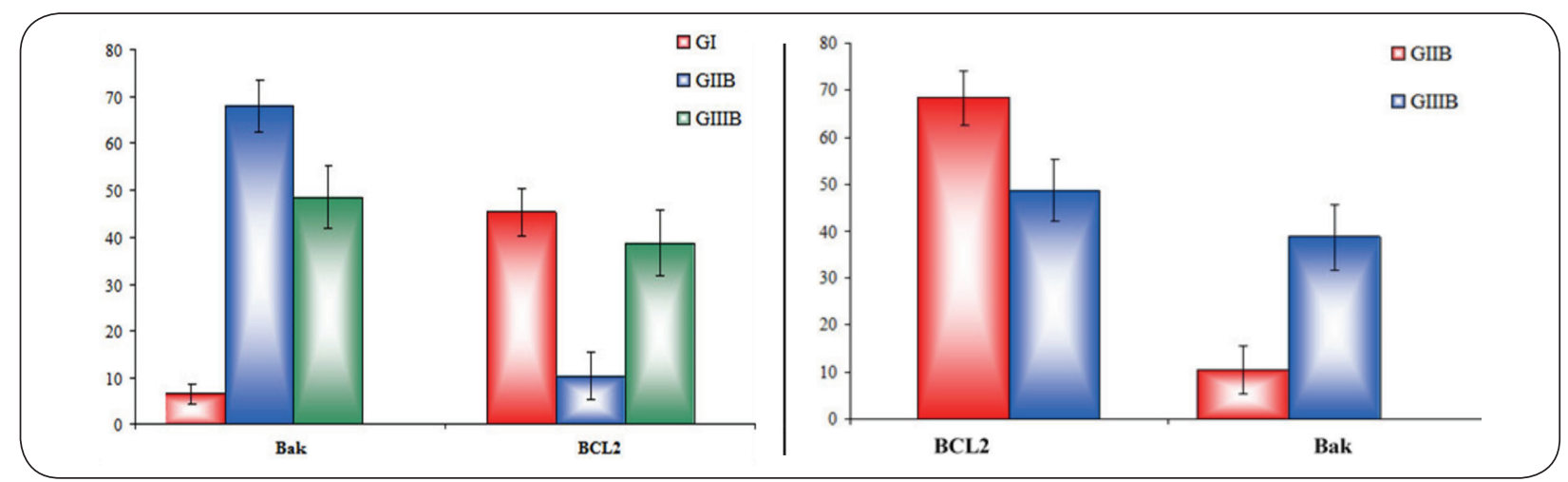

Chart (2): Bar chart representing mean area \% results of Bcl-2 \& Bak (A) in GI, GIIB \& GIIIB at 14 weeks (B) in GIIB \& GIIIB at 14 weeks. 


\section{DISCUSSION}

Globally, therapeutic approaches to cancer include chemotherapy, radiation therapy and surgery which are frequently associated with severe side effects $^{(12)}$. Furthermore, treatment strategies for OSCC are diverse due to the unpredictable behavior of the cancer, local invasion, frequent regional lymph node metastases and a relative resistance to chemotherapeutic drugs leading to an unpredictable prognosis. More ever, traditional treatment for oral precancerous is total surgical excision that always leads to scar formation for a large precancerous lesion. The consensus is that the reversal of precancerous lesions or protection from malignant transformation would have a great impact on the prevention and treatment of OSCC $^{(13)}$. Extensive studies highlighted the chemopreventive effects of diverse natural products ${ }^{(14,15)}$. The present study, on gross observation, revealed the positive effect of HT as chemopreventive agent on DMBA induced HBP carcinogenesis. Moreover, the results of $\mathrm{H} \& \mathrm{E}$ stain and IHC staining utilizing Bcl-2 and Bak antibodies revealed variable observations. The HBP oral carcinogenesis model in the current study was used because is the best known animal system that closely correlates with sequential common events involved in the development of human oral premalignant and malignant lesion ${ }^{(16)}$.

In the current study, the duration of DMBA application was carefully planned according to the previous literatures, at 8 weeks for the animals of GII A in order to achieve development of intact epithelial dysplasia, but not invasive SCC, and at 14 weeks for the animals of GII B in order to achieve development of invasive OSCC ${ }^{(16,17)}$. In the present study, the chemopreventive agent has been administered one week before and during carcinogen administration following the protocol of previous studies ${ }^{(18,19)}$.

In the present study, the gross observation findings in GI (negative control) those having received no treatment but used to record, if any, the changes related to the time of experimental periods, showed no observable gross changes, HBP appeared normal, with smooth surface. After being euthanized, the buccal pouches length was about $5 \mathrm{~cm}$ for all hamsters with normal histological structures. These results are in agreement with those of other studies ${ }^{(20,21)}$. These findings reflected on H\&E stain that showed keratinized stratified squamous epithelium, subepithelial C.T formed of small amount of sporadic fibrocytes and blood vessels which present between the epithelium and the muscular layer. These results are in consistence with that reported by Baskaran et al (2017) ${ }^{(22)}$. IHC staining of GI showed positive cytoplasmic expression of Bcl-2 cytoplasmic expression $(6.77 \%)$ that was seen to be restricted to the basal and supra-basal layers and negative in the remaining epithelial cell layers. This result is in agreement with that of other investigators $^{(23,24)}$. This observation might be attributed to that up regulation of Bcl-2 in basal and supra-basal cells serves to maintain the keratinocyte stem cells from apoptosis $^{(25)}$. Furthermore these results agree with the suggestion of Kummoona et al $(2008)^{(26)}$, that Bcl-2 plays a role in the control of terminal differentiation of keratinocytes through the protection of basal cells of the proliferative compartment against apoptosis, thus guaranteeing structural epithelial integrity. Negative Bcl-2 expression in the remaining epithelial layers is concomitant with terminal cell differentiation (keratinization) ${ }^{(27)}$. In contrast, staining with Bak expression was positive cytoplasmic $(45.32 \%)$ and seen in all layers of the epithelium. These results are in agreement with those of other investigators $^{(12,28)}$. These results could be attributed to that Bak a proapoptotic protein, is present in viable cells to increase the susceptibility of apoptosis of unwanted cells and induce apoptosis in reaction to genotoxic stress so protects the cells from neoplastic transformation ${ }^{(29)}$. Under normal conditions, p53 stimulates the up-regulation of Bak and down regulation of $\mathrm{Bcl}-2$ to remove the unwanted cells from the host ${ }^{(28)}$.

In the present study, the gross observation findings of GIIA (DMBA treated group at 8 weeks) 
showed variable changes, these included whitish and erythematous areas with multiple small elevated nodules surrounded with ulcerative and hemorrhagic areas in HBP mucosa. These results are almost similar with those shown by other investigators ${ }^{(30,31)}$. These observations were reflected by histopathological results: a moderate to severe epithelial dysplasia were seen. The changes in histopathological status of this group and their timing were similar to other studies ${ }^{(30,31)}$. These observations could be attributed to the effects of DMBA as carcinogen which include formation of DNA adducts, induction of chronic inflammation, overproduction of ROS and oxidative DNA damage, there by leading to neoplastic transformation ${ }^{(32)}$. IHC staining of HBP mucosa GIIA with Bcl-2 antibody showed highly significantly increasing expression compared to normal group, there was highly significant difference between GI and GIIA where $p$ value was $<0.001$. There was high significant difference between GI and GIIA where $p$ value was $<0.001$ while with Bak antibody a high significant difference was compared to normal group (GI). These results are in agreement with other studies ${ }^{(33,34)}$. Bcl-2 protein, the gene product of $\mathrm{Bcl}-2$ proto-oncogene, is an anti-apoptotic protein which extends the survival of genetically damaged cells as well as facilitates neoplastic transformation. Contrarily, Bak induces apoptosis in reaction to genotoxic stress and thus protects the cells from neoplastic transformation. Therefore, the significant of overexpression of Bcl2 and down-regulation of Bak protein suggests that buccal tissues from hamsters painted with DMBA escaped from the apoptotic cascade ${ }^{(14)}$.

In the present study, the gross observation of the right HBP mucosa of GIIB (DMBA treated group at 14 weeks) showed multiple exophytic masses of variable size surrounded with area of ulceration and hemorrhage. Furthermore, some animals are debilitated. These results are almost similar with those shown by other investigators used the same proto$\mathrm{col}^{(14,35)}$. Histopathological results of GIIB showed that animals exhibit well differentiated OSCC with evidence of keratin formation. Tumor cells consisting of pleomorphic, hyperchromatic nuclei exhibited altered nuclear/cytoplasmic ratio. Papillary projections of parakeratinised squamous epithelium into the connective tissue were also seen. These observations are in consistence with those of other studies ${ }^{(16,36)}$. In the present study, the Bcl-2 immune staining results revealed extensive positive cytoplasmic expression (68.37\%) throughout the epithelial layers except the most superfacial layer (keratin) and there was highly significant difference between GI and GIIB where p value was $<0.001$. These results are in agreement with those of other studies $^{(12,14,15,35)}$. Literature data regarding the expression of Bcl-2 during the progression of OSCC are controversial. Some investigators reported only weak or no expression of this protein ${ }^{(37,38)}$. The Bak immune staining results revealed positive cytoplasmic expression (10.38\%) throughout the epithelial layers except the most superfacial layer (keratin) and there was significant difference between GI and GIIB where $p$ value was 0.014 . These results are in agreement with those of other studies ${ }^{(12,14,15,39)}$. The increased level of Bcl-2 expression indicated that, inhibition of apoptosis by prevention the release of cytochrome $\mathrm{C}$ from mitochondria and promotion of carcinogenesis, While the decreased expression of Bak could be due to reduced apoptotic cell death as well as accelerated their growth ${ }^{(32,40)}$.

The results of the current study demonstrated that oral administration HT inhibit the cell proliferation of OSCC and induce apoptotic cell death. Gross observation of the right HBP mucosa of GIIIA (chemoprevention group): HT at week before, as well as, during the application of DMBA, 3 times a week on alternative days for 8 weeks showed decrease in distribution and size of the nodules, ulceration and hemorrhagic areas compared to GIIA at the same period. These findings reflected by H\&E stain in which 3 animals with normal epithelium, and 6 showed hyperkeratosis and hyperplasia, while one revealed mild epithelial dysplasia. IHC staining utilizing Bcl-2 and Bak antibodies in GIIIA at 8 weeks 
also revealed different results in each model of this group. In GIIIA model, Bcl-2 revealed positive cytoplasmic expression except the most superfacial layer (keratin) (16.07\%) with high significant difference between GIIA and GIIIA where $p$ value was $<0.001$ while Bak revealed positive cytoplasmic expression except the most superfacial layer (keratin) (19.32\%), with high significant difference between GIIA and GIIIA where $p$ value was $<0.001$. These results are concomitant with those observed by other investigators ${ }^{(41,35)}$.

The aforementioned results could be attributed to that HT prevents ROS generation in normal and tumor cells, suggesting that it can also prevent oxidative damage in both cell types, thereby preventing both initiation and promotion/progression of tumor genesis. However, antioxidant effects occurring in an installed malignant disease, where the oxidative status is altered should be interpreted carefully ${ }^{(42)}$. Fabini et al (2008) ${ }^{(53)}$ showed that HT prevents oxidative DNA damage in human normal blood mononuclear cells, and suggested that HT may efficiently prevent the initiation step of carcinogenesis in vivo. These results suggest that HT can inhibit ROS production, can prevent oxidative DNA damage in normal and non-transformed cells in vitro, thereby preventing the initiation of a chain of reactions that transforms normal into cancer cells. This hypothesis is supported by an intervention study showed that the supplementation of postmenopausal women with high phenol extra virgin olive oil (EVOO) caused decreased oxidative damage to lymphocyte $\mathrm{DNA}^{(44)}$.

In the present study, gross observation of the right HBP mucosa of GIIIB (chemoprevention group) HT at week before, as well as, during the application of DMBA, 3 times a week on alternative days for 14 weeks showed variable changes including erythematous mucosal surface with diffuse swelling and/or multiple small exophytic nodules surrounded with ulcerative and hemorrhagic areas. These findings reflected on H\&E stain in which, 4 animals exhibited well differentiated SCC, 4 ex- hibited severe epithelial dysplasia, and 2 exhibited moderate epithelial dysplasia. In GIIIB model, Bcl2 revealed moderate positive cytoplasmic expression $(48.81 \%)$ and there was highly significant difference between GIIB and GIIIB where $p$ value was $<0.001$ while Bak revealed positive cytoplasmic expression (38.72\%). There was high significant difference between GIIB and GIIIB where $p$ value was $<0.001$. These results are concomitant with those observed by other investigators ${ }^{(45,46)}$. EVOO, a unique functional food with a major contribution to the health-promoting effects of the Mediterranean diet that contains a natural inhibitor of HT and DNA methyltransferases (DNMTs) capable of specifically and potently suppressing the functional traits of cancer stem cell (CSC) within heterogeneous cancer cell populations, might open new avenues for introducing innovations in CSC-targeted therapy based on the molecular bridge that connects metabolism and epigenetics with the state of stemness ${ }^{(47-48)}$.

The present study indicated that there was a statistically significant reverse correlation between area percentage of $\mathrm{Bcl}-2$ and that of Bak expression $(r=-0.268)(p-v a l u e=0.025)$. This means that an increase in one variable is associated in decrease in the other and vice versa. Animals with a high Bcl2/ Bak expression ratio had a significantly poorer prognosis than those with a low Bcl-2/ Bak ratio. Other chemoprevention studies pointed out impairment in the balance between proliferation and apoptotic activities in the tumor tissues of different cancers including oral cancer ${ }^{(41,49)}$. Jain et al (2013) ${ }^{(50)}$ found that, the ratio of $\mathrm{Bcl}-2 / \mathrm{Bak}$ expression appeared to be the best variable in predicting disease specific survival in OSCC .

\section{REFERENCES}

1. Pereira K, Feitosa S, Tomaz A, Lima E, Cavalcante R, De Lima $\mathrm{K}$ et al. Immunohistochemical evaluation of glucose transporter type 1 in epithelial dysplasia and oral squamous cell carcinoma. Asian Pacific J Cancer Preve 2016; 17: $147-51$. 
2. Aruna D, Prasad K, Shavi G, Ariga J, Rajesh G, Krishna M. Retrospective study on risk habits among oral cancer patients in Karnataka Cancer Therapy and Research Institute, Hubli, India. Asian Pac J Cancer Prev 2011; 12: 1561-66.

3. Manoharan S, Silvan S, Vasudevana K, Baskaran N, Kumar S, Vinoth K. Carnosic acid, a potent chemopreventive agent in oral carcinogenesis. Chem Biol Interact 2010; 188: 616-22.

4. Vinothkumar V, Manoharan S. Chemopreventive efficacy of geraniol against 7, 12- dimethylbenz (a) anthracene induced hamster buccal pouch carcinogenesis. Redox Rep 2011; 16: 91-100.

5. Kumar G, Tajpara P, Maru G. Dietary turmeric post-treatment decreases DMBA-induced hamster buccal pouch tumor growth by altering cell proliferation and apoptosisrelated markers. J Environ Pathol Toxicol Oncol 2012; 31: 295-312.

6. Manimaran A, Manoharan S. Tumor preventive efficacy of emodinin 7, 12- dimethylbenz (a) anthracene induced oral carcinogenesis: Ahistopathological and biochemical approach. Pathol Oncol Res 2017; 1-11.

7. Shanmugam M, Singh A, Nagarethinam B, Sekar K. Proapoptotic and anti-inflammatory potential of andrographolide during 7, 12- dimethylbenz (a) anthracene induced hamster buccal pouch carcinogenesis. J Exp Integr Med 2012; 2: 313-19.

8. Fernandez-Bolanos J, Lopez O, Fernandez-Bolanos J, Rodriguez- Gutiérrez G. Hydroxytyrosol and derivatives: Isolation, synthesis, and biological properties. Curr Org Chem 2008; 12: 442-63.

9. Sabatini N. Recent patents in olive oil industry: new technologies for the recovery of phenols compounds from olive oil, olive oil industrial by-products and waste waters. Recent Pat Food Nutr Agric 2010; 2: 154-59.

10. Cao K, Xu J, Zou X, Li Y, Chen C, Zheng A et al. Hydroxytyrosol prevents diet-induced metabolic syndrome and attenuates mitochondrial abnormalities in obese mice. Free Radic Biol Med 2014; 67: 396-407.

11. Zhao B, Ma Y, Xu Z, Wang J, Wang F, Wang D et al. Hydroxytyrosol, a natural molecule from olive oil, suppresses the growth of human hepatocellular carcinoma cells via inactivating AKT and nuclear factor-kappa B pathways. Cancer Lett 2014; 347: 79-87.

12. Babukumar S, Vinothkumar V, Velu P, Ramachandhiran D, Ramados Nirmal M. Molecular effects of hesperetin, a cit- rus flavanone on 7,12-dimethylbenz(a)anthracene induced buccal pouch squamous cell carcinoma in golden Syrian hamsters. Arch Physiol Biochem 2017; 123: 265-78.

13. De Souza F, Oliveira M, Nunes M, Serafim L, Azambuja A, Braga L et al. Sunitinib improves some clinical aspects and reverts DMBA-induced hyperplasic lesions in hamster buccal pouch. ISRN Otolaryngol 2014; 8: 59-621.

14. Vinothkumar V, Manoharan S. Chemopreventive efficacy of geraniol against 7,12-dimethylbenz[a]anthracene-induced hamster buccal pouch carcinogenesis. Redox Rep 2011; 16: 91-100.

15. Karthikeyan S, Manoharan S. Cromolyn inhibits 7, 12dimethylbenz (a) anthracene induced oral cancer through apoptotic induction and suppression of cell proliferation. Int J Pharma Bio Sci 2016; 7: 35-42.

16. Katoumas K, Nikitakis N, Perrea D, Dontas I, Sklavounou A. In vivo antineoplastic effects of the NSAID sulindac in an oral carcinogenesis model. Cancer Prev Res (Phila) 2015; 8: 642-49.

17. Nishimura N, Urade M, Hashitani S, Noguchi K, Manno Y, Takaoka K et al. Increased expression of cyclooxygenase (COX)-2 in DMBA-induced hamster cheek pouch carcinogenesis and chemopreventive effect of a selective COX-2 inhibitor celecoxib. J Oral Pathol Med 2004; 33: 614-21.

18. Kumar G, Tajpara P, Maru G. Dietary turmeric post-treatment decreases DMBA-induced hamster buccal pouch tumor growth by altering cell proliferation and apoptosisrelated markers. J Environ Pathol Toxicol Oncol 2012; 31 : 295-312.

19. Wang W, Chen C, Hsu H, Lin L, Chen Y. Chemopreventive effect of Toona sinensis leaf extract on 7, 12- dimethylbenz (a) anthracene induced hamster buccal pouch squamous cell carcinogenesis. Arch Oral Biol 2016; 70: 130-42.

20. Casto B, Knobloch T, Galioto R, Yu Z, Accurso B, Warner B. Chemoprevention of oral cancer by lyophilized strawberries. J Anticancer Res 2013; 33: 4757- 66.

21. Manimaran A, Manoharan S. Tumor preventive efficacy of emodin in 7,12-dimethylbenz[a]anthracene induced oral carcinogenesis: a histo-pathological and biochemical approach. Pathol Oncol Res 2017;10: 1-10.

22. Baskaran N, Selvam G, Yuvaraj S, Abhishek A. Parthenolide attenuates 7,12-dimethylbenz[a]anthracene induced hamster buccal pouch carcinogenesis. Mol Cell Biochem 2017; 10:1-8. 
23. Rajasekaran D, Manoharan S, Silvan S, Vasudevana K, Baskaran N, Palanimuthu D. Proapoptotic, anti-cell proliferative, anti-inflammatory and antiangiogenic potential of carnosic acid during 7, 12 dimethylbenz (a) anthraceneinduced hamster buccal pouch carcinogenesis. Afr J Tradit Complement Altern Med 2012; 10: 102-12.

24. Arya V, Singh S, Daniel M. Clinicopathological correlation of Bcl-2 oncoprotein expression in oral precancer and cancer. J Oral Biol Craniofac Res 2016; 6: 19-24.

25. Singh B, Chandler F, Whitaker S, Forbes-Nelson A. Immunohistochemical evaluation of Bcl-2 oncoprotein in oral dysplasia and carcinoma. Oral Surg Oral Med Oral Pathol Oral Radiol Endod 1998; 85: 692-98.

26. Kummoona R, Sámi M, Al-Kapptan I, Al-Muala H. Study of antiapoptotic gene of oral carcinoma by using Bcl-2 oncogene. J Oral Pathol Med 2008; 37: 345-51.

27. Garewal J, Garewal R, Sircar K. Expression of Bcl-2 and MIB-1 markers in oral squamous cell carcinoma (OSCC) a comparative study. J Clin Diagn Res 2014; 8: 1-4.

28. Manoharan S, Vasanthaselvan M, Silvan S, Baskaran N, Singh A, Kumar V. Carnosic acid: A potent chemopreventive agent against oral carcinogenesis. Chem Biol Interact 2010; 188: 616- 22.

29. Karlberg M, Ekoff1 M, Labi V, Strasser A, Huang D, Nilsson G: Pro-apoptotic Bax is the major and Bak an auxiliary effector in cytokine deprivation-induced mast cell apoptosis. Cell Death and Disease 2010; e43.

30. Chen Y, Lin L. DMBA-induced hamster buccal pouch carcinoma and VX2-induced rabbit cancer as a model for human oral carcinogenesis. Expert Rev Anticancer Ther 2010; 10: 1485-96.

31. Vidya Priyadarsini R, Senthil Murugan R, Nagini S. Aberrant activation of Wnt/ $/$-catenin signaling pathway contributes to the sequential progression of DMBAinduced HBP carcinomas. Oral Oncol 2012; 48: 33-39.

32. Manoharan S, Sindhu G, Nirmal M, Vetrichelvi V, Balakrishnan S. Protective effect of berberine on expression pattern of apoptotic, cell proliferative, inflammatory and angiogenic markers during 7,12- dimethylbenz (a) anthracene induced hamster buccal pouch carcinogenesis. Pakistan J Biol Sci PJBS 2011; 14: 918-32.

33. Pitiyage G, Tilakaratne W, Tavassoli M, Warnakulasuriya S. Molecular markers in oral epithelial dysplasia: review. J Oral Pathol Med 2009; 38: 737-52.
34. Nair R, Shameena P, Varghese I. Immunohistochemical evaluation of Bcl-2 oncoprotein in oral dysplasia and carcinoma. Oral Maxillofac 2011; 2: 83-108.

35. Kavitha K, Kowshik J, Kishore T, Baba A, Nagini S. Astaxanthin inhibits NF- $\chi B$ and $\mathrm{Wnt} / \beta$-catenin signaling pathways via inactivation of Erk/MAPK and PI3K/Akt to induce intrinsic apoptosis in a hamster model of oral cancer. Biochim Biophys Acta Gen Subj 2013; 1830:4433-44.

36. Vijayalakshmi A, Sindhu G. Dose responsive efficacy of umbelliferone on lipid peroxidation, anti-oxidant, and xenobiotic metabolism in DMBA-induced oral carcinogenesis. Biomed Pharmacother 2017; 88: 852-62.

37. Schoelch M, Le Q, Silverman S, McMillan A, Dekker N, Fu K et al. Apoptosis-associated proteins and the development of oral squamous cell carcinoma. Oral Oncol 1999; 35: 77-85.

38. McAlinden R, Maxwell P, Napier S, Hamilton p, Cowan $\mathrm{C}$, Lundy $\mathrm{F}$ et al. Bcl-2 expression in sequential biopsies of potentially malignant oral mucosal lesions assessed by immunocytochemistry. Oral Dis 2000; 6: 318-26.

39. Karthikeyan S, Manoharan S. Cromolyn inhibits 7, 12dimethylbenz (a) anthracene induced oral cancer through apoptotic induction and suppression of cell proliferation. Int J Pharma Bio Sci 2016; 7: 35-42.

40. Manoharan S, Rajasekaran D, Murugaraj M, Karthikeyan S, Manimaran A. Modulating effect of enicostemma littorale on the expression pattern of apoptotic, cell proliferative, inflammatory and angiogenic markers during 7,12 dimethylbenz[a]anthracene-induced hamster buccal pouch carcinogenesis. Toxicol Int 2015; 22: 130- 40.

41. Rosignoli P, Fuccelli R, Sepporta M, Fabiani R. In vitro chemo-preventive activities of hydroxytyrosol: the main phenolic compound present in extra-virgin olive oil. Food Funct 2016; 7: 301-07.

42. Fabiani R, Sepporta M, Rosignoli P, Bartolomeo A, Crescimanno M, Morozzi G. Anti-proliferative and proapoptotic activities of hydroxytyrosolon different tumour cells: the role of extracellular production of hydrogenperoxide. Eur J Nutr 2012; 51: 455-64.

43. Fabiani R, Rosignoli, P, De Bartolomeo A, Fuccelli R, Servili M, Montedoro G et al. Oxidative DNA damage is prevented by extracts of olive oil, hydroxytyrosol and other olive phenolic compounds in human blood mononuclear cells and HL60 cells. J Nutr 2008; 138: 1411-16.

44. Warleta F, Quesada C, Campos, M, Allouche Y, Beltràn G, Gaforio J. Hydroxytyrosol protect against oxidative DNA damage in human breast cells. Nutrients 2011; 3: 839-57. 
45. Granados-Principal S, Quiles L, Ramirez-Tortosa C, Camacho-Corencia P, Sanchez-Rovira P, Vera-Ramirez L et al. Hydroxytyrosol inhibits growth and cell proliferation and promotes high expression of sfrp4 in rat mammary tumours. Mol Nutr Food Res 2011; 55: 117-26.

46. Martínez-Martos J, Mayas M, Carrera P, Arias de Saavedra J, Sánchez-Agesta R. Phenolic compounds oleuropein and hydroxytyrosol exert differential effects on glioma development via antioxidant defense systems. J Funct Foods 2014; 11: 221-34.

47. Casaburi I, Puoci F, Chimento A, Sirianni R, Ruggiero C, Avena $\mathrm{P}$ et al. Potential of olive oil phenols as chemopreventive and therapeutic agents against cancer: a review of in vitro studies. Mol Nutr Food Res 2013; 57: 71-83.

48. Menendez J. The meta bolo epigenetic dimension of cancer stem cells: evaluating the market potential for new metabostemn esstargeting oncology drugs. Curr Pharm 2015; 21: 3644-53.

49. Han J, Talorete T, Yamada P, Isoda H. Anti-proliferative and apoptotic effects of oleuropein and hydroxytyrosol on human breast cancer MCF-7 cells. Cytotechnology 2009; 59: 45-53.

50. Jain M, Kasetty S, Sudheendra U, Nitin J, Samar K, Ami D. Apoptosis and its significance in oral diseases: An Update. J Oral Dis 2013;1-11. 
مجلة أسيوط لطب الأسنان

النشر الرسمي لكلية طب الأسنان

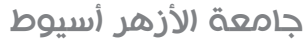

\section{تقييم الكفاءة الوقائية لمادة الهيدروكسى تروسول علي

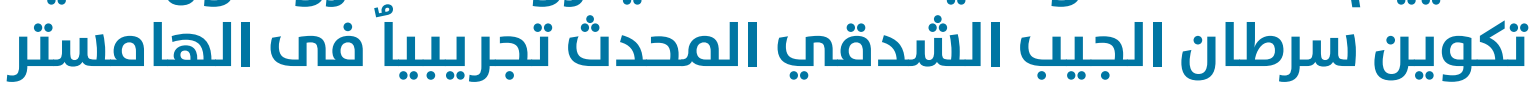

طه عمرى على احملد, عمرو سعد عبد الوهاب*, محمد جمعه عطيـه زعير قسم امراض الفم، كلية طب الاسنان، جامعة الازهر، (القاهره، بنين) )، مصر AMRSAAD.10@AZHAR.EDU.EG:البريد الالكترونى * (الملخص :

الهدف: أجريت هذه إلرسالة البحثية لتقييم الكفاءة الوقائية لمادة الهيدروكسى تروسـول علي تكوين سـرطان الجيب

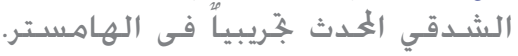

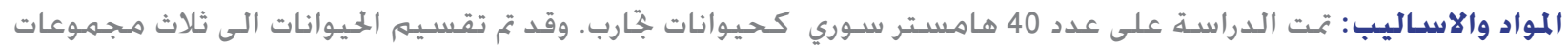

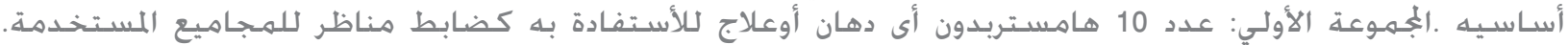

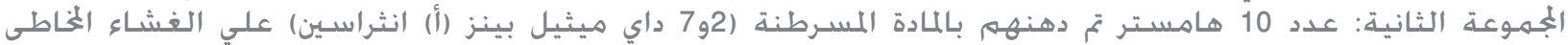

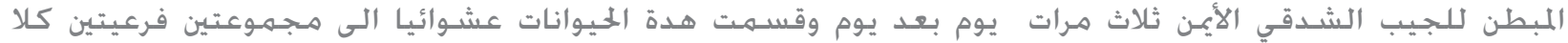

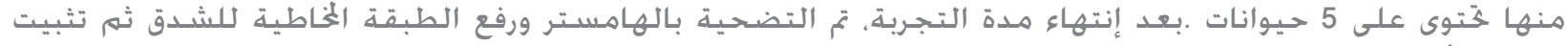

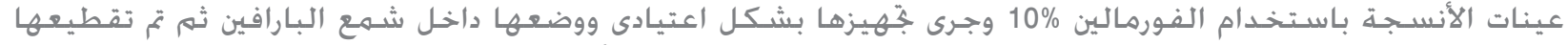

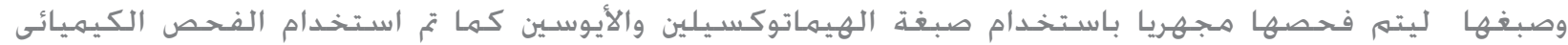

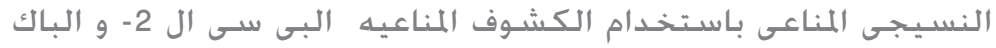

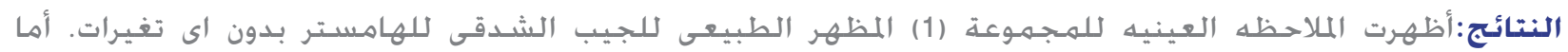

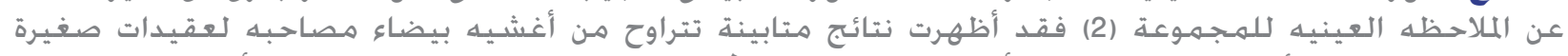

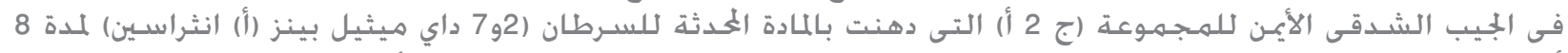

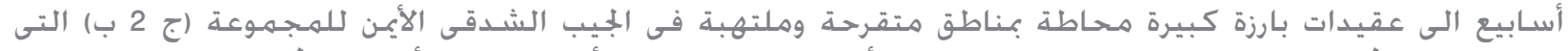

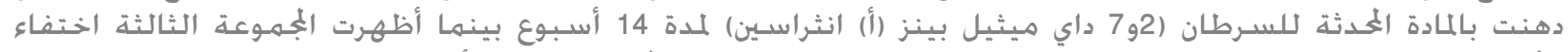

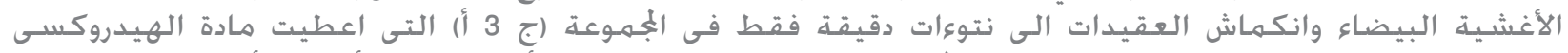

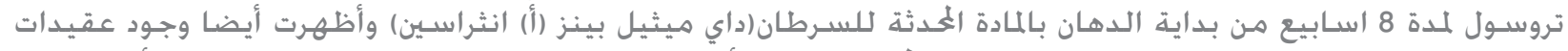

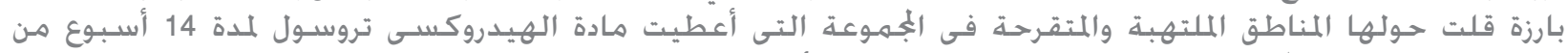

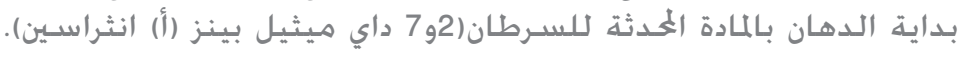

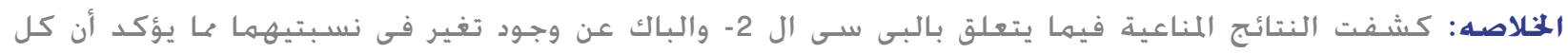

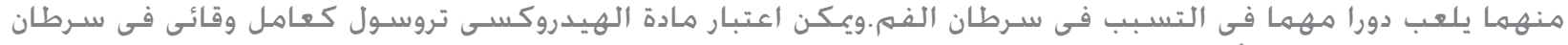
الفم وانخفاض معدل الأصابه بـه.

الكـلمات المفتاحيه: الجيب الشـدقى بحيوانات الهامستير, سـرطان الاغشيه الخخاطيه، الهيدروكسى تروسـول، وقاية

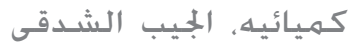

